\title{
Influence of Access Cavity Design on Fatigue Resistance of Reciproc Blue: Conservative vs. Truss Access
}

\author{
Giacomo Corsentino* \\ Department of Endodontics and Restorative Dentistry, University of Siena, Italy
}

*Corresponding author: Giacomo Corsentino, Department of Endodontics and Restorative Dentistry, University of Siena, Siena, Italy

\begin{abstract}
Introduction: Several factors including the access to the root canal systems could influence the fatigue of rotating or reciprocating endodontic instruments. The aim of this study was to assess the effect of conservative (CAC) and truss access cavity (TAC) preparation on the cyclic fatigue resistance of endodontic nickel-titanium (NiTi) files.

Methods: A total of sixty extracted human intact mandibular molars were selected and assigned to CAC or TAC group ( $\mathrm{n}$ $=30$ ). All samples received root canal treatment. A total of 60 Reciproc blueTM R25 (VDW GmbH, Munich, Germany) files were used for root canal shaping (a new file for each tooth). Then, all 60 instruments were tested to cyclic fatigue by counting the time to fracture (TtF) in an artificial stainless steel canal with $60^{\circ}$ of angle and $5-\mathrm{mm}$ of radius of curvature. Data were statistically analyzed by independent T-test and the significance level was set at $5 \%$.
\end{abstract}

Results: Cyclic fatigue resistance of Reciproc blue ${ }^{\mathrm{TM}} \mathrm{R} 25$ was significantly reduced by its use in endodontically treated teeth with TAC $(P<0.05)$. There was no statistically significant difference in the mean length of the fractured fragments of the files $(P>0.05)$.

Conclusions: Within the limitations of the present in vitro study, Truss Access Cavity causes more fatigue of Reciproc blue $^{\mathrm{TM}}$ R25 than Conservative Access Cavity.

\section{Introduction}

Nickel-Titanium (NiTi) endodontic instruments enable efficient mechanical preparation of the root canal with reduction of iatrogenic errors, such as transportation or perforation [1]. Nevertheless, they are subjected to fatigue stress, sometime until their fracture, during root canal treatment [2]. NiTi files may be fracture for two main reasons: Torsion, when a portion of the instru- ment is locked in root canal, while the remaining part continues to rotate over the alloy torsion elastic limit [3]; cyclic fatigue, when an instrument rotates inside of a curved root canal and it is subject to an excessive number of deformation cycles tension-compression in the region of maximum curvature of the root canal $[2,4]$.

The introduction of reciprocating motion reduces the risk of instruments' fracture during instrumentation [5]. Indeed, endodontic files activated by reciprocating movement is purported to always work below their elastic limit extending their cyclic fatigue life [68]. The factors involved in endodontic files failure may be directly related to its design: Dimensions at the tip, taper, cutting efficiency, alloy $[9,10]$, manufacturing process [10]. However, fracture variables of NiTi instruments may also depend on external factors such as curvature and radius of root canal, speed of rotation [11], type of movement and number of sterilization cycles $[9,12]$. Therefore, each of these parameters was object of studies previously. Although there is no available evidence, many endodontists prefer, whenever possible, to perform "contracted" endodontic cavity access preparations as "truss" (TAC) or conservative access cavity (CAC) to ensure greater resistance to fracture of endodontically-treated teeth. The "contracted" access cavities used as an alternative to traditional access are: "Conservative access", "ninja access" and "truss access" (Figure 1). Conservative access is considered a viable approach that maintains tooth structure and offers the ability to easily and safely carry out the root canal treatment [13]. In the ninja access, a small hole is performed approximately in the middle of the occlusal sur-

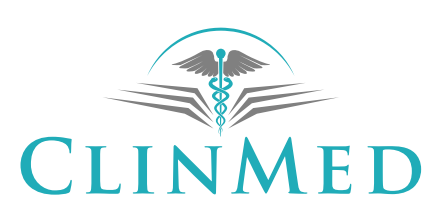

INTERNATIONAL LIBRARY 


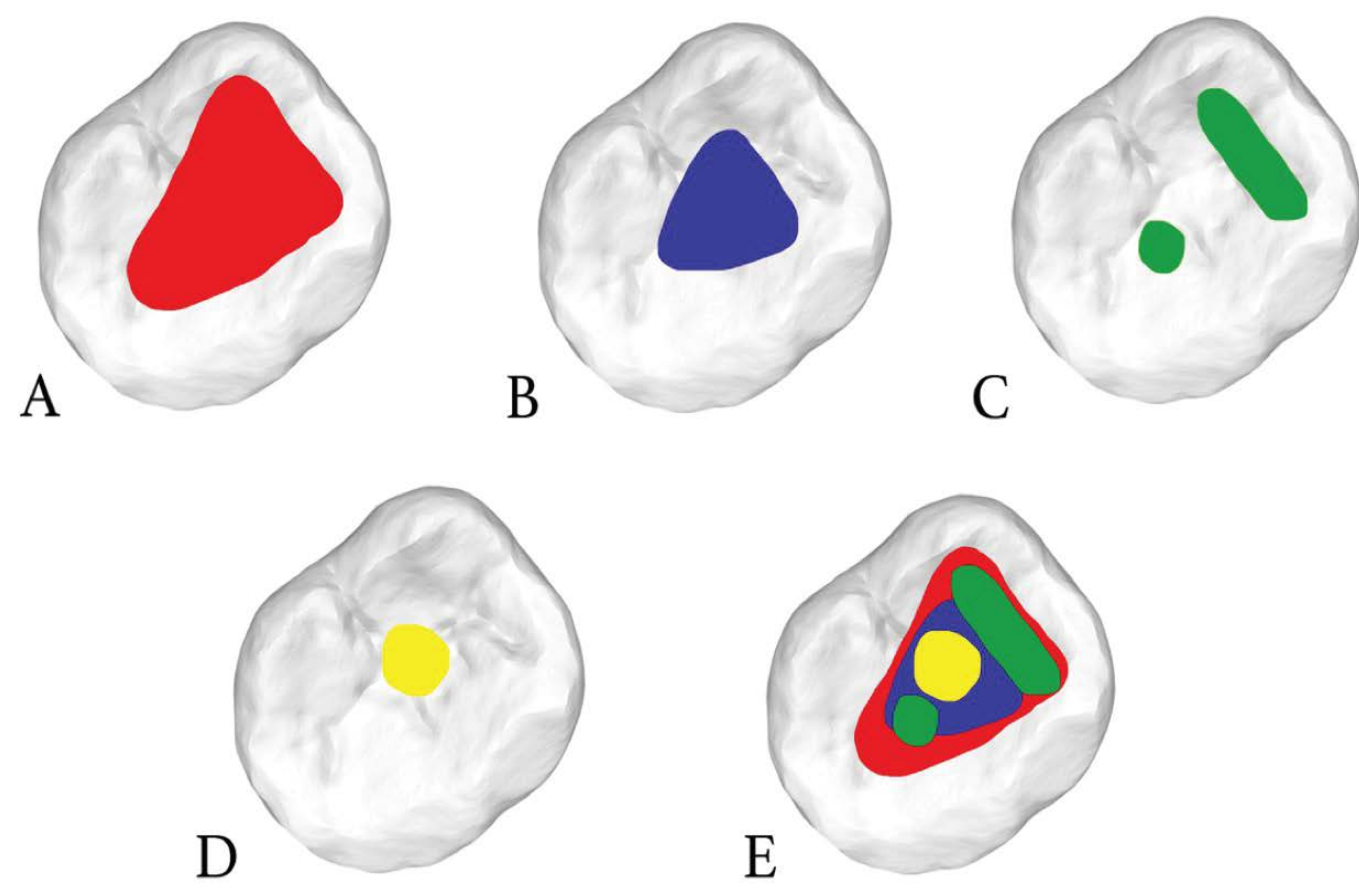

Figure 1: Sketches of different endodontic access cavity designs. A) Traditional; B) Conservative; C) Truss; D) Ninja; E) Superimposition of different access cavities in the same occlusal surface of a first mandibular molar.

face. This approach does not seem to provide adequate space for proper execution of the following treatment steps, but little scientific evidence is currently available regarding that technique [14]. Truss access is performed exclusively for multi-canaled teeth because it involves the maintenance of part of the chamber roof and an enamel-dentin bridge through direct access to each canal [15].

"Contracted" endodontic access cavities could not be able to create a straight-line access to the root canal creating at least 2 points of maximum flexure of the NiTi files: One at the canal orifice and one at the root canal curvature [16]. This clinical situation could often create a double curvature that could reduce the mechanical fatigue resistance of endodontic NiTi files. There is no information in literature about the effect of different cavity access designs on the fatigue of endodontic NiTi instruments. Therefore, the aim of this study was to compare the effect of two different cavity preparations (TAC and CAC) on the fatigue of Reciproc ${ }^{\mathrm{TM}}$ blue files.

\section{Materials and Methods}

The study protocol was approved by the Ethics Committee. Sixty sound extracted (for periodontal reasons) mandibular molars with completely formed apices, moderate curved root canals, without caries or restorations were selected and stored in $0.9 \%$ saline solution at $4{ }^{\circ} \mathrm{C}$, inside individually numbered containers, to prevent dehydration. Inclusion criteria were as follows: Two separate mesial canals with separate apical foramina and a non oval single distal root canal confirmed by periapical radiographs in a mesio-distal and bucco-lingual projection; similar root shape with angles of cur- vature between $10^{\circ}$ and $20^{\circ}$ measured by Schneider's method [17] and a radius below $10 \mathrm{~mm}$ [18] measured using digitized buccolingual radiographs and AxioVision 4.5 software (Carl Zeiss Vision, Hallbergmoos, Germany) [19]. The anatomic crown height was measured from the occlusal surface to the cement-enamel junction on all 4 sides of the teeth; buccolingual and mesiodistal (MD) dimensions were measured at the occlusal surface. Tooth measurements were taken with a digital caliper (Digimatic 500; Mitutoyo, Kanagawa, Japan). Specimens were subsequently assigned to 2 groups ( $n$ $=30$ ) that were homogenous on the basis of tooth and root canal dimensions averages:

- Group A (Figure 2A), conservative access cavity (CAC) group;

- Group B (Figure 2B), truss access cavity (TAC) group.

Molars length was standardized at $19( \pm 1) \mathrm{mm}$ by a small reduction of the cusps in order to create repeatable reference points for the following instrumentation.

Then the teeth were drilled with size 856 diamond burs (Komet Italia srl, Milan, Italy) mounted on a high speed hand piece with water cooling [20]. Molars of group $A$, opened with CAC, were accessed at the mesial quarter of the central fossa, and cavities were extended apically and distally while maintaining part of chamber roof. Mesial-distal, buccal-lingual, and circumferential pericervical dentin removal was minimized to ensure the maintenance of part of chamber roof compatible with the localization of all root canal orifices [13]. Molars of group B were opened with TAC. The principle of TAC is to maintain part of the chamber roof to achieve a more conservative opening. So it was necessary to measure, 


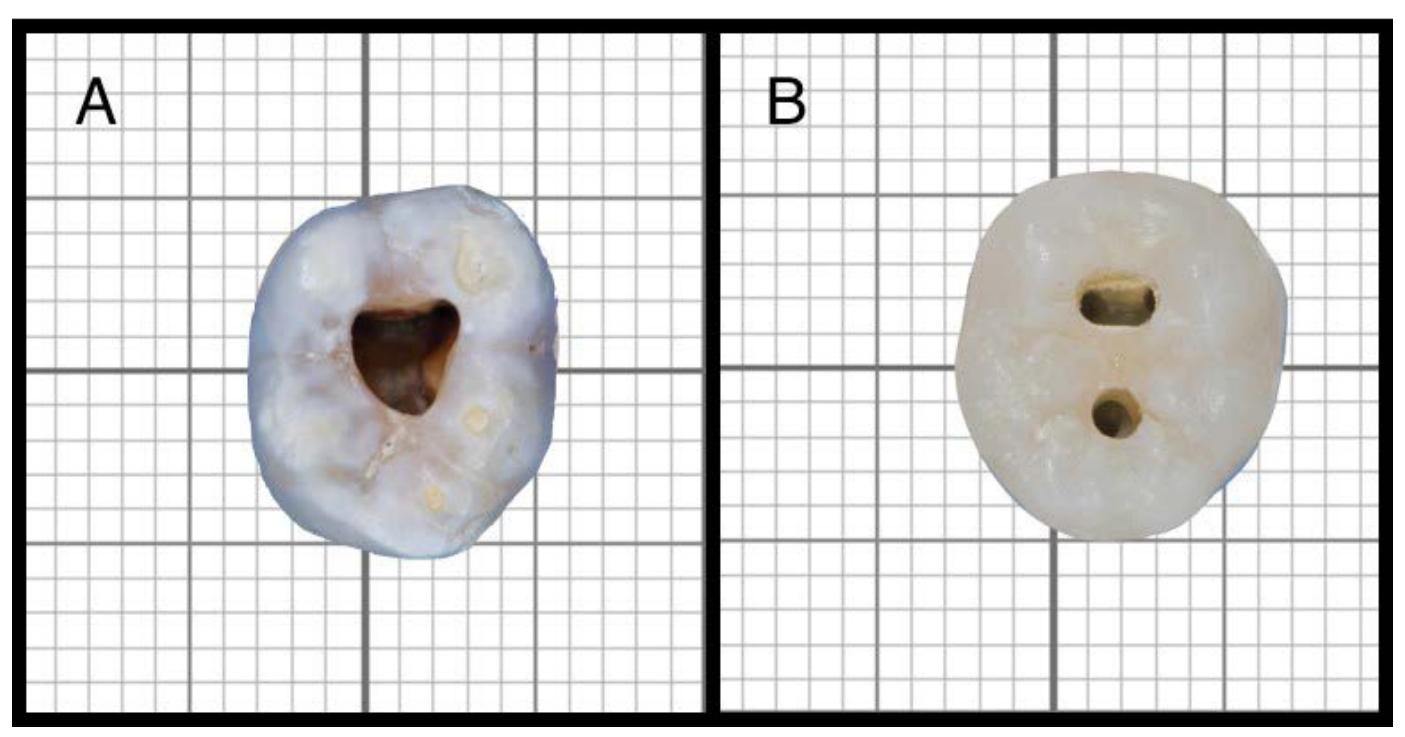

Figure 2: "Contracted" endodontic access cavities performed on the occlusal surface of first mandibular molars samples. A) Conservative access cavity (CAC); B) Truss access cavity (TAC).

on X-rays with a periodontal probe (UNC 15, Hu Friedy, Chicago, IL), the distance between marginal ridge and canal orifices, in order to try to locate, on the occlusal surface, the correct position and direction where to use the bur. After that, a single access to mesial canals was created with buccal-lingual direction and another one, circular, distally to reach the distal root canal, so the two access on the same occlusal surface were separated by an enamel/dentin bridge. After access cavity was completed, size $10 \mathrm{~K}$-files (Dentsply/Maillefer, Ballaigues, Switzerland) were used to explore the root canal until the instrument tip was seen at the apical foramen using a stereomicroscope. This measure was recorded as the patency length and the working length $(\mathrm{WL})$ was set $0.5 \mathrm{~mm}$ shorter [20].

Sixty new Reciproc blue ${ }^{\mathrm{TM}} \mathrm{R} 25$ (VDW GmbH, Munich, Germany) were used in this study. Each Reciproc was inspected with a stereoscopic microscope (SZR-10 Optika SRL, Ponteranica, Italy) at a magnification of $80 \mathrm{X}$, to evaluate defects and deformities, none was discarded.

A new Reciproc blue R25 was used for shaping root canals of a single tooth in reciprocating motion activated by using a 6:1 reduction hand piece (Sirona Dental Systems $\mathrm{GmbH}$, Bensheim, Germany) powered by a torque-controlled motor (Silver Reciproc, VDW) using the preset program "Reciproc ALL". After root canal irrigation with $2 \mathrm{~mL} 5 \% \mathrm{NaOCl}$ (Niclor 5 dentale. Ogna Lab srl, Muggiò, Italy), the Reciproc instrument was placed in the canal until resistance was felt and then activated. In sequence, it was moved in an apical direction using in-and-out pecking motions, with 2-3 $\mathrm{mm}$ amplitude. After 3 pecking motions, the instrument was removed, cleaned and the canal irrigated with $2 \mathrm{~mL} 5 \% \mathrm{NaOCl}$. Patency of the canal was checked using a size $10 \mathrm{~K}$-file. These procedures were repeated twice until the WL was reached by the Reciproc instrument. Each Reciproc instrument was used to prepare only one canal. The ca- nal was then irrigated with $5 \mathrm{~mL} 5 \% \mathrm{NaOCl}$. Final rinsing with $5 \mathrm{~mL} 17 \%$ EDTA and $5 \mathrm{~mL} 5 \% \mathrm{NaOCl}$ was done for smear layer removal. All irrigation procedures were carried out using 30-gauge NaviTip needles (Ultradent, South Jordan, UT, USA) placed $2 \mathrm{~mm}$ short of the WL. After that, each Reciproc Blue R25 was tested to cyclic fatigue using an artificial stainless steel canal with $60^{\circ}$ angle and $5-\mathrm{mm}$ radius of curvature placed into a custom made device already validated in literature [21,22]. All tested instruments were inserted $19 \mathrm{~mm}$ into the artificial canal that was sprayed with lubricating oil (Super Oil; Singer Co. Ltd, Elizabethport, NJ, USA) to reduce the friction between the file and the walls of the artificial canal. The instruments were activated by using the same hand piece, torque-controlled motor and preset program used to shape the molar root canals. All instruments were rotated until failure. The time was recorded and stopped as soon as a fracture was detected visually and/or audibly. The length of fractured file tip was measured by using a digital microcaliper (Mitutoyo, Kawasaki, Japan). Scanning electron microscope (Jeol 6060, Jeol, Tokyo, Japan) analysis of the fragments was performed at 180x magnifications looking for topographic features of fractured surface of instruments used to prepare teeth with CAC or TAC.

The Kolmogorov-Smirnov test was used to verify the normality of data distribution for both groups separately and the Levene's test was performed to analyse the homogeneity of group variances. Thus, data were statistically evaluated by Independent T-Test (Prism 5.0; GraphPad Software, Inc, La Jolla, CA) with the significance level established at $5 \%(P<0.05)$.

\section{Results}

Mean time to fracture (seconds) and fragment lengths $(\mathrm{mm})$ with their standard deviations and standard error means are reported in Table 1. Independent 
T-Test revealed that cyclic fatigue resistance of instruments used to prepare root canals of teeth with TAC was significantly reduced than the one of Reciproc Blue R25 used to shape root canals of teeth with CAC design $(P<0.05)$.

The mean length of the fractured fragment $(5.1 \mathrm{~mm})$ was not significantly different for all of the instruments tested $(P>0.05)$.

Scanning electron microscopy of fracture surface showed similar and typical features of cyclic fatigue for both instruments used in teeth with TAC or CAC. The crack initiation area and overload fast fracture zone for cyclic fatigue fractures are shown in Figure 3.

\section{Discussion}

Ideal endodontic access cavity should allow, at the same time, direct access to the root canal with complete elimination of the pulp and minimal removal of sound dentine in order to preserve mechanical resistance under masticatory function of endodontically treated teeth [15]. An incomplete access cavity could reduce the emptying quality and may alter the shape of root canal preparation [23] an exceeded access cavity could favor perforations, compromise the biomechanic performance of root treated teeth and expose the tooth to coronary/root fracture [22]. Studies have shown that after caries removal and cavity preparation, the dimin-

Table 1: Time to fracture (Ttf) and Length of fractured fragments $(\mathrm{mm})$ of reciproc blue R25 used in one first mandibular molar with truss access cavity (TAC) or conservative access cavity (CAC).

\begin{tabular}{|l|l|l|l|l|}
\hline \multirow{2}{*}{$\begin{array}{l}\text { Endodontic } \\
\text { access cavity }\end{array}$} & \multicolumn{2}{|l|}{$\begin{array}{l}\text { Cyclic fatigue } \\
\text { (TtF) (seconds) }\end{array}$} & \multicolumn{2}{l|}{$\begin{array}{l}\text { Fractured fragment } \\
\text { length }(\mathbf{m m})\end{array}$} \\
\cline { 2 - 5 } & Mean & SD & Mean & SD \\
\hline CAC & $742.5^{\mathrm{a}}$ & 188.949 & $5.18^{\mathrm{a}}$ & 0.16 \\
\hline TAC & $631.6^{\mathrm{b}}$ & 199.737 & $5.12^{\mathrm{a}}$ & 0.18 \\
\hline
\end{tabular}

The same letters in a column show differences not statistically significant $(P>0.05)$.

SD: Standard deviation. ished strength of the remaining tooth is directly proportional to the amount of structure lost [24,25]. Therefore, different cavity preparations as well as different endodontic access cavity designs could differently reduce tooth fracture strength [26]. Following the minimal invasive dentistry principles, "contracted" cavity accesses were proposed for root canal treatment [27].

In this study the influence of "contracted" endodontic access cavities like truss and conservative designs on cyclic fatigue resistance of Reciproc Blue R25 was evaluated. Only first lower molars were used because they have a more regular anatomy than others. In these teeth it is possible to studies are required to create two openings separated by an enamel-dentin bridge as required by TAC design. A mesial opening stretching in the buccal-lingual direction, allowing access to both mesial canals, and a smaller distal opening, allowing direct access to the distal canal. "Contracted" endodontic access cavity as TAC and CAC allows to saving healthy tissue, however, on the other hand, it could negatively affect the remaining procedures of the root canal treatment, making them harder and less predictable. The operator has to work in a reduced space that limits visibility and complicates the use of the root canal instruments [28]. Even if, it has been shown that "contracted" endodontic cavities do not impact instrumentation efficacy and biomechanical tooth response [29], there are many factors to take into consideration, regarding the shaping procedure of endodontically treated teeth. Among these, there is also an increased risk of instrument fracture during the shaping of curved canals due to a difficult and no straight-line access $[16,30]$. Indeed, most clinical guidelines and manufacturers' instructions for instrumentation with NiTi files recommend the creation of straight-line access and the reduction of interferences in the middle and coronal third [31]. In this study, Reciproc blue R25 files used in teeth with TAC had significantly less fatigue than the ones used in teeth with CAC. Although it is not possible to directly compare the results of this study with other reports due to the absence of data in literature, these findings are reasonable because
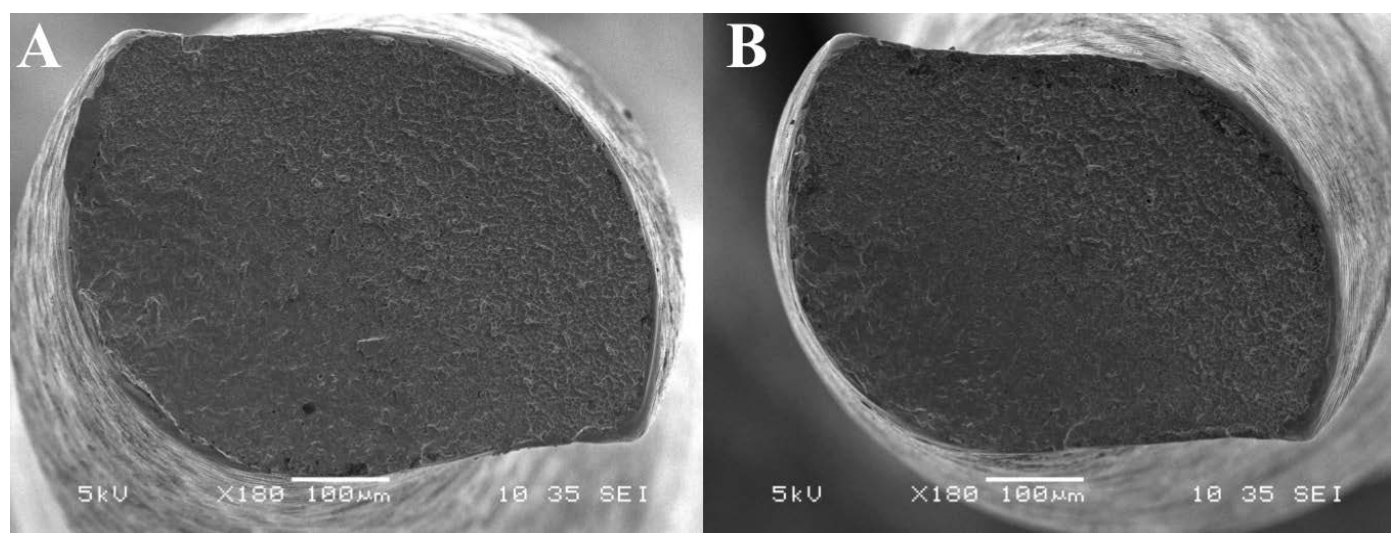

Figure 3: Scanning electron micrographs of fracture surface of separated fragments of Reciproc blue R25 used to shaping tooth with CAC (A) or TAC (B). Surface pattern shows dimples, and cones in the same fracture plane. 
"contracted" access cavities did not allow a straight-line access often creating at least 2 points of maximum flexure of the file [16]. In this case, like in cases of a NiTi instrument that rotates inside a double curvature, the synergistic effect of the two curvatures reduced significantly the fatigue resistance of the file [32].

The scanning electron microscopic analysis showed typical fractographic appearances of cyclic fatigue fractures [2,22] for instruments used in teeth with both kind of endodontic access designs tested. This confirms that fractographic findings correspond to those ones due to the last stress applied (cyclic fatigue test in this study) [33].

Moreover, when a "contracted" endodontic access cavity is performed, endodontic NiTi instruments could simultaneously enter in contact with a great amount of dental tissue during its shaping movement. In this way, the torque generated during canal preparation could increase due to the augmented contact area between the instrument and root canal as well as "contracted" endodontic access cavity walls [34]. Thus, in cases with complex anatomy (e.g. severely curved or narrow root canals), where greater stress of the instrument is expected [35], CAC should be preferred to TAC. Within the limitations of this in vitro study, TAC results in greater cyclic fatigue of the Reciproc blue ${ }^{\mathrm{TM}} \mathrm{R} 25$ file than CAC, in mandibular endodontically treated first molars. However, further evaluate all aspects involved in the use of "contracted" access cavity design before that it's use could be recommended in daily clinical practice.

\section{References}

1. Glossen CR, Haller RH, Dove SB, del Rio CE (1995) A comparison of root canal preparations using $\mathrm{Ni}-\mathrm{Ti}$ hand, $\mathrm{Ni}-\mathrm{Ti}$ engine-driven, and K-Flex endodontic instruments. $\mathrm{J}$ Endod 21: 146-151.

2. Parashos $\mathrm{P}$, Messer $\mathrm{HH}$ (2006) Rotary NiTi instrument fracture and its consequences. J Endod 32: 1031-1043.

3. Sattapan B, Palamara JE, Messer HH (2000) Torque during canal instrumentation using rotary nickel- titanium files. $J$ Endod 26: 156-160.

4. Martín B, Zelada G, Varela P, Bahillo JG, Magán F, et al. (2003) Factors influencing the fracture of nickel-titanium rotary instruments. Int Endod J 36: 262-266.

5. De Deus G, Moreira EJL, Lopes HP, Elias CN (2010) Extended cyclic fatigue life of F2 ProTaper instruments used in reciprocating movement. Int Endod J 43: 1063-1068.

6. Varela Patino P, Ibanez Parraga A, Rivas Mundina B, Cantatore G, Otero XL, et al. (2010) Alternating versus continuos rotation: A comparative study of the effect on instrument life. J Endod 36: 157-159.

7. Kim HC, Kwak SW, Cheung GSP, Ko DH, Chung SM, et al. (2012) Cyclic fatigue and torsional resistance of two new nickel-titanium instruments used in reciprocation motion: Reciproc versus WaveOne. J Endod 38: 541-544.

8. Pedullà E, Grande NM, Plotino G, Gambarini G, Rapisarda $E$ (2013) Influence of continuous or reciprocating motion on cyclic fatigue resistance of 4 different nickel-titanium rotary instruments. J Endod 39: 258-261.
9. Hilt BR, Cunningham CJ, Shen C, Richards N (2000) Torsional properties of stainless-steel and nickel-titanium files after multiple autoclave sterilizations. J Endod 26: 76-80.

10. Gambarini G, Grande NM, Plotino G, Somma F, Garala $M$, et al. (2008) Fatigue resistance of engine-driven rotary nickel-titanium instruments produced by new manufacturing methods. J Endod 34: 1003-1005.

11. Daugherty DW, Gound TG, Comer TL (2001) Comparison of fracture rate, deformation rate, and efficiency between rotary endodontic instruments driven at $150 \mathrm{rpm}$ and 350 rpm J Endod 27: 93-95.

12. Silvaggio J, Hicks ML (1997) Effect of heat sterilization on the torsional properties of rotary nickel-titanium endodontic files. J Endod 23: 731-734.

13. Clark D, Khademi JA (2010) Case studies in modern molar endodontic access and directed dentin conservation. Dent Clin North Am 54: 275-289.

14. Plotino G, Grande NM, Isufi A, loppolo P, Pedullà E, et al. (2017) Fracture strength of endodontically treated teeth with different access cavity designs. J Endod 43: 995-1000.

15. Buchanan LS (2015) Cutting endodontic access cavities-for long term outcomes. Oral health.

16. Bahcall JK, Carp S, Miner M, Skidmore L (2005) The causes, prevention, and clinical management of broken endodontic rotary files. Dent Today 24: 74-80.

17. Schneider SW (1971) A comparison of canal preparations in straight and curved root canals. Oral Surg Oral Med Oral Pathol Oral Radiol Endod 32: 271-275.

18. Freire LG, Gavini G, Cunha RS, Md S (2012) Assessing apical transportation in curved canals: Comparison between cross-sections and micro-computed tomography. Braz Oral Res 26: 222-227.

19. Marceliano Alves MF, Sousa Neto MD, Fidel SR, Steier L, Robinson JP, et al. (2015) Shaping ability of single-file reciprocating and heat-treated multifile rotary systems: A micro-CT study. Int Endod J 48: 1129-1136.

20. Pedullà E, Plotino G, Grande NM, Avarotti G, Gambarini $\mathrm{G}$, et al. (2016) Shaping ability of two nickel-titanium instruments activated by continuous rotation or adaptive motion: A micro-computed tomography study. Clin Oral Investig 20: 2227-2233.

21. Larsen CM, Watanabe I, Glickman GN, He J (2009) Cyclic fatigue analysis of a new generation of nickel titanium rotary instruments. J Endod 35: 401-403.

22. Pedullà E, Corsentino G, Ambu E, Rovai F, Campedelli $F$, et al. (2017) Influence of continuous rotation or reciprocation of optimum torque reverse motion on cyclic fatigue resistance of nickel-titanium rotary instruments. Int Endod $\mathrm{J}$ 51: $522-528$.

23. Estrela C, Pécora JD, Estrela CRA, Guedes OA, Silva BSF, et al. (2017) Common operative procedural errors and clinical factors associated with root canal treatment. Braz Dent J 28: 179-190.

24. Soares PV, Souza PG, Souza SC, de Queiroz Gonzaga RC, Faria VLG, et al. (2013) Effects of non-carious lesions and coronary structure loss association on biomechanical behavior of maxillary premolars. J Res Dent 1: 140-153.

25. Pereira JR, McDonald A, Petrie A, Knowles JC (2013) Effect of cavity design on tooth surface strain. J Prosthet Dent 110: 369-375.

26. Teixeira ES, Rizzante FA, Ishikiriama SK, Mondelli J, Furuse $A Y$, et al. (2016) Fracture strength of the remaining 
dental structure after different cavity preparation designs. Gen Dent 64: 33-36.

27. Kaidonis JA, Skinner VJ, Lekkas D, Winning TA, Townsend GC (2013) Reorientating dental curricula to reflect a minimally invasive dentistry approach for patient-centred management. Aust Dent J 58: 70-75.

28. Caicedo R, Clarck S, Rozo L, Joseph F (2008) Guidelines for access cavity preparation in endodontics.

29. Moore B, Verdelis K, Kishen A, Dao T, Friedman S (2016) Impacts of contracted endodontic cavities on instrumentation efficacy and biomechanical responses in maxillary molars. J Endod 42: 1779-1783.

30. Iqbal MK, Kohli MR, Kim JS (2006) A retrospective clinical study of incidence of root canal instrument separation in an endodontics graduate program: A PennEndo database study. J Endod 32: 1048-1052.

31. Zelada G, Varela P, Martín B, Bahíllo JG, Magán F, et al. (2002) The effect of rotational speed and the curvature of root canals on the breakage of rotary endodontic instruments. J Endod 8: 540-542.

32. Al-Sudani D, Grande NM, Plotino G, Pompa G, Di Carlo S, et al. (2012) Cyclic fatigue of nickel-titanium rotary instruments in a double (S-shaped) simulated curvature. J Endod 38: 987-989.

33. Pedullà E, Lo Savio F, Plotino G, Grande NM, Rapisarda $S$, et al. (2015) Effect of cyclic torsional preloading on cyclic fatigue resistance of ProTaper Next and Mtwo nickel-titanium instruments. Giornale It Endod 29: 3-8.

34. Blum JY, Cohen A, Machtou P, Micallef JP (1999) Analysis of forces developed during mechanical preparation of extracted teeth using Profile NiTi rotary instruments. Int Endod J 32: 24-31.

35. Peng C, Hui WU, Wang L, Xin HU, Deng S, et al. (2015) Cyclic fatigue resistance of two nickel-titanium instruments in different curving angles: A comparative study. Braz Oral Res 29: 1-7. 